Tsunami: unexpected blow foils flawless warning system

The trans-Pacific tsunami generated by the magnitude- 8.8 Chile earthquake on 27 February exposed a problem with

Australia's tsunami earlywarning system.

Since the 2004 Indian Ocean tsunami, the Australian government has spent Aus $\$ 70$ million (US\$64 million) on the development and deployment of the Australian Tsunami Warning System (ATWS). This is jointly operated by the Australian Bureau of Meteorology and Geoscience Australia.

On 27-28 February, the system worked flawlessly in detecting the earthquake and issuing first watch messages, then warning messages for Australia via numerous channels. The smooth operation of the physical hardware of the ATWS is a credit to all the government scientists who have been working tirelessly since December 2004. Unfortunately, the final element of the ATWS - the community's response - failed.

The Chilean tsunami was forecast to arrive at Sydney at about 8.30 in the morning on 28 February. Despite widespread television and radio broadcasts of the tsunami warning, live television coverage showed hundreds of people standing on beaches waiting for the tsunami to arrive. Worse, some of them were deliberately swimming into the incoming tsunami, despite the efforts made by volunteers from Surf Life Saving Australia to prevent this.

These people may not have received the warning messages, or they may not have understood the risk, or they may have deliberately ignored the advice issued.

What became clear is that we need a better understanding of the social dimension of public response to warning messages in Australia, and the emergency services need more resources for community education.

Dale Dominey-Howes, James Goff Australian Tsunami Research Centre, University of New South Wales, High Street, Kensington 2052, New South Wales, Australia e-mail:dale.dh@unsw.edu.au

\section{Tsunami: time for models to be tested in warning centres}

You highlight, in a News story, the controversy over the reliance of tsunami early-warning systems on model-based forecasts (Nature 464, 14-15; 2010). Important advances have been made in near-real-time model-based tsunami forecasting since 2004 , by scientists such as those at the US Pacific Marine Environmental Laboratory, the German Research Centre for Geosciences and the European Commission's scientific and technical reference arm, the Joint Research Centre (JRC).

These advances make the models important contributors to tsunami-warning systems.

The Intergovernmental

Oceanographic Commission (IOC) of the United Nations Educational, Social and Cultural Organization can help to guide the optimal use of such forecasts to improve the effectiveness of existing early-warning systems.

The JRC has been developing a global tsunami-modelling system, which is integrated into the joint United Nations/ European Commission Global Disaster Alert and Coordination System (GDACS; www.gdacs. org). It is based on a global pre-event calculated tsunami scenario grid and near-realtime simulated forecasts. This combined approach gives an almost instantaneous estimate of wave height and arrival times, as well as enabling a warning to be issued within 20 minutes of an earthquake-inducing tsunami.

The system worked effectively after the Chilean earthquake, with alerts transmitted via SMS and e-mail to some 10,000 GDACS users within 30 minutes; the JRC accurately predicted the height of the tsunami near Concepcion. The risk for the Pacific islands was considered low because of the wave's conditions at the source, with a sea-level rise of less than a metre expected in Hawaii.

The Portuguese Institute of Meteorology is already testing the reliability of forecasts with an early-warning system that will provide a framework for the IOC's future northeast Atlantic regional centre.

It is time for forecasting models to be tested systematically in operational conditions by the tsunami-warning centres. These will complement the arrays of tidal and deep-sea gauges by filling information gaps where gauges are scarce, to minimize false alarms. The challenge is to identify how to formalize the integration of model-based forecasts into the process of issuing warnings.

Delilah H. A. Al Khudhairy, Alessandro Annunziato Global Security and Crisis Management Unit, Institute for the Protection and Security of the Citizen, Joint Research Centre, Ispra, Italy e-mail:delilah.al-khudhairy@ ec.europa.eu

\section{Researchers' petition aims to simplify European funding}

Your call for simplification of European research funding (Nature 463, 999; 2010) is timely. In February we started a pan-European petition for simplification of the funding rules, addressed to the European Parliament and the Council of Ministers. So far, more than 7,300 researchers have signed up at www.trust-researchers.eu.

The petition aims to give a voice to researchers all over Europe who want to change the way research is funded (see page 349). Right now, many stakeholder discussions are taking place inside and outside the European Commission to simplify the rules.
That is promising. We welcome feedback from the broad research community. Olivier Küttel Euresearch, Effingerstrasse 19, 3008 Bern, Switzerland e-mail: contact@trust-researchers.eu Sabine Herlitschka Austrian Research Promotion Agency, Austria

\section{Smoking out the big tobacco-users - and they're not in China}

The photograph of an Asian person puffing on a cigarette and the map of the top cigaretteconsuming countries, both shown in J. M. Samet and H. L. Wipfli's Opinion article (Nature 463, 1020-1021; 2010), make China look like a smokers' paradise.

Its large population may make China the top consumer of cigarettes in the world. But, as is shown more clearly in the online version of the Tobacco Atlas map (http://go.nature.com/jQNEWc), the populations of many other countries, especially in Europe, smoke more per person - the heaviest smokers being in Greece and Ukraine.

Jie-Yu Chuang Department of Psychiatry, Tri-Service General Hospital, National Defense Medical Center, Taipei, Taiwan e-mail: simone@mail.ndmctsgh.edu.tw

\section{Waterfall is the clue to a case of mistaken identity}

A photograph (Nature 463, 1007; 2010) captioned to imply that it shows the coastline of Monterey Bay actually shows the cove at the mouth of McWay Canyon, about $50 \mathrm{~km}$ south of Monterey Bay. The give-away is the ribbon waterfall plunging over the sea cliff from the mouth of the canyon.

William R. Dickinson Department of Geosciences, University of Arizona, Box 210077, Tucson, Arizona 85718, USA e-mail: wrdickin@dakotacom.net 